\title{
Spermatogonial Stem Cells Protein Marker Identification from in vitro Differentiation of Non- Obstructive Azoospermia (NOA) Testes Biopsies Cells: An approach In Line with Maqasid Shariah to Maintain the Heredity
}

\author{
Azantee Yazmie Abdul Wahab ${ }^{1,3}$, Roszaman Ramli ${ }^{1,3}$,Syamsul Ahmad Ariffin ${ }^{2,4}$, Afzan Mat Yusuf ${ }^{2,4}$, Redzuan \\ Abd Razak ${ }^{2,4}$, Afif Raihan Ahmad ${ }^{5}$, Husin Muhammad ${ }^{6}$, Lokman Md Isa ${ }^{2,4}$ \\ ${ }^{1}$ Department of Obstetrics \& Gynaecology (O\&G), Kulliyyah of Medicine, International Islamic University \\ Malaysia (IIUM) Kuantan \\ ${ }^{2}$ Department of Basic Medical Science Nursing (BMSN), Kulliyyah of Nursing, IIUM Kuantan \\ ${ }^{3}$ IIUM Fertility Centre, IIUM Kuantan \\ ${ }^{4}$ IIUM Human Cellular and Molecular Biology Research Cluster (iMolec), IIUM Kuantan \\ ${ }^{5}$ Department of Biomedical Science, Kulliyyah of Allied Health Sciences, IIUM Kuantan \\ ${ }^{6}$ Institute for Medical Research, Jalan Pahang, 50588 Kuala Lumpur, Malaysia
}

\begin{abstract}
Azoospermia is present in $15 \%$ of infertile cases and it is a major concern due to inability to produce sperm. Most of IVF (in-vitro fertilization) clinics abroad has been using sperm donation via sperm bank facilities as a solution for infertile couple to have their own offspring. In Islam, it is forbidden to use sample from male other than their spouse. It is according to maqasid syari'ah to ensure the heredity of the human being. Based on the latest technology, one approach of stem cell differentiation process had been established to produce mature cells from primitive or immature cells (stem cells). This technology is in line with the concept of maqasid syari'ah since we are using the cells from one person. We try to adopt this technology to study the potential of testicular cells from non-obstructive azoospermic (NOA) patient to undergo in vitro spermatogenesis. Samples were cultured in modified human embryonic stem cells (HESC) media with specific growth factors; basic fibroblast growth factor (bFGF) and leukemia inhibitory factor (LIF). Protein expressions were analyzed by immunofluorescent staining on day 49 and 90 of culture. Results show spermatogonial stem cell-like cells (SSC-like cells) colonies formed after 14 to 21 days, the cells were expanding successfully and were stable for 49 days duration. Then SSCs differentiated into later stage of spermatogenesis on day 90. Four specifics SSCs protein markers were identified on day 49; ITGA1, ITGB1, CD9 and GFRA1 whereas SCP3 and TP1 proteins were expressed on day 90. This in vitro spermatogenesis suggests a possible approach for future for Muslim NOA patients in order to have their own children.
\end{abstract}

KEYWORDS: Azoospermic, spermatogenesis in-vitro, maqasid syari'ah

\section{INTRODUCTION}

Azoospermia is defined as absence of sperm in the ejaculated semen, which results in male infertility. It is present in $1 \%$ of all men and $10 \%$ to $15 \%$ of infertile men. ${ }^{4}$ There are two types of azoospermia; obstructive azoospermia (OA) and non-obstructive azoospermia (NOA). Intracytoplasmic sperm injection (ICSI) has become the standard male infertility treatment especially for OA cases where sperm can be derived from the

Corresponding author:

Muhammad Lokman Md Isa

Department of Basic Medical Sciences,

Kulliyyah of Nursing

IIUM Human Cellular and Molecular Biology Cluster (iMoleC)

International Islamic University Malaysia

Jalan Sultan Ahmad Shah, 25200 Kuantan

Telephone: +6012 9645581

Email: lokman@iium.edu.my epididymis or testis through sperm retrieval procedure. ${ }^{5}$ However, in NOA cases, it is challenging and very difficult to treat due to inability to produce spermatozoa. To date, there is hardly any study that reports the production of successful spermatozoa from these patients. In certain NOA cases, ICSI was done using round spermatid. However, the fertilization and implantation rates are poor. ${ }^{6}$

In vitro culture of immature germ cells to mature stage has been approached to improve the outcome. Spermatogenesis in vitro has long been attempted mostly in animal studies, but it remains challenging due to restriction of culture systems. Only limited studies have been performed using human samples.Spermatogenesis process has unique microenvironmental niche that requires growth factors, hormones and somatic cells to achieve development into spermatozoa. ${ }^{3}$ Human embryonic stem cell (HESC) media were widely used for embryonic stem 
IMJM Volume 17 Special Issue No 2

cell culture and some of these studies had derived the male germ cells from embryonic stem cells. ${ }^{2,7,17,21}$ Thus, this media could possible initiate the SSCs-like cell from adult testicular stem cells.

In most countries, azoospermia patients may opt to have children using spermatozoa from a donor. In Islam, it is forbidden for couple to use donor gametes to have children. Malaysia is a Muslim country whereby most of the citizens practice Islam. Therefore, the purpose of this study is to initiate spermatogenesis in vitro using testicular cells from NOA patient samples using modified HESC media with specific growth factors and hormones. This study is carried out to determine the protein markers involved in the proliferation and differentiation of spermatogenic cells from the beginning until the end of culture.

\section{MATERIALS AND METHODS}

\section{Tissue preparation}

Testicular cell samples were obtained from the testicular sperm extraction (TESE) procedure at IIUM Fertility Centre, Kuantan, Pahang, Malaysia. Informed consent was given from the patient prior to participation. Briefly, the testes biopsies were placed on a $35 \mathrm{~mm}$ petri dish and added with handling GMOPS media (Vitrolife, Sweden). The biopsies were dissociated mechanically using scissors to obtain testicular cells. The cells were aspirated and placed into a $15 \mathrm{ml}$ conical Falcon tube (Becton Dickinson Labware, USA) and added with sperm washing media (Sage, USA). The samples were centrifuged at $1000 \mathrm{rpm}$ for 10 minutes. The visualized pellets then were washed with red blood cells lysis buffer (Life Technologies, USA) and centrifuged at 1000rpm for 5 minutes to eliminate the red blood cells. The pellets were added to trypsin enzyme media (Life Technologies, USA) and incubated for 5 minutes at $37^{\circ} \mathrm{C}$ with $5 \% \mathrm{CO}^{2}$ humidity. The samples then were added with sperm wash media and centrifuged at 1000rpm for 5 minutes. The samples were washed again with the same media to eliminate the unwanted digested debris. The visualized pellets are prepared for cell culture.

\section{Cell culture}

Samples divided into two groups: HESC media consisting of knockout DMEM, knockout serum replacement, L- glutamine, 2-mercaptoethanol, gentamicin and basic fibroblast growth factor (BFGF) and same HESC media with additional of leukemia inhibitory factor (LIF). All preparation samples were cultured in a 24-well dish and incubated at $37^{\circ} \mathrm{C}$ with $5 \% \mathrm{CO}^{2}$ humidity. The culture media in each sample was replaced with new media on alternate days. After 49 days of culture, each of the sample group had extended culture by adding recombinant follicle stimulating hormone $(\mathrm{rFSH})$ and testosterone hormone until 90 days.

Identification of protein marker by immunofluorescence (IF) staining
Cells were preserved by fixation prior to immunofluorescence staining to detect specific cell surface markers. The culture medium was removed from the well and cells were washed with 1x PBS. Then, the cells in culture well were fixed with $4 \%$ PFA for 1 hour at room temperature. The $4 \%$ of PFA was prepared by heating the mixture of $4 \mathrm{~g}$ of PFA and $100 \mathrm{~mL}$ of PBS on heating plate at $65^{\circ} \mathrm{C}$ and constantly stirred the mixture until it totally diluted. After PFA was removed and cells were washed 3 times with 1x PBS supplemented with 5\% FBS. Primary antibodies were added to the culture wells containing $1 x$ PBS $+5 \%$ FBS at a specific dilution based on the recommendation given in the data sheet of the product. After that, all the samples were incubated at room temperature for 1 hour. Primary antibody was then removed and cells were washed 3 times with $1 \mathrm{x}$ PBS $+5 \%$ FBS. Secondary antibody was added into the culture well at the recommended dilution ratio and incubated for 1 hour at room temperature. The culture well was covered with aluminium foil to protect from light. Then, secondary antibody was removed and the cells were washed 3 times with $1 x$ PBS $+5 \%$ FBS. 4'6'-Diamidino-2 phenylindole (DAPI) $(1 \mathrm{mg} / \mathrm{mL})$ was used for nuclear visualisation. DAPI was diluted at $1: 1000$ in a specific dilution of PBS $+5 \%$ FBS. DAPI was incubated in each well for 1 hour. The cells were visualised under a fluorescence microscope and photomicrographs were captured.

\section{RESULTS}

\section{Cell propagation}

SSCs colonies on Day 49 of culture in NOA patient samples were present in HESC medium with BFGF (Figure $1 \mathrm{~A}$ ), and HESC medium with BFGF and LIF (Figure 1B). After 90 days, the cell activity reduced in HESC medium with BFGF (Figure $1 \mathrm{C}$ ) whereas SSCs colonies increased in HESC medium with BFGF and LIF (Figure 1D).

\section{Protein markers using IF staining}

Figure 2 shows expression of SSCs surface protein markers using IF staining from NOA patient sample cultured with HESC and BFGF medium. Results were positive for ITGB1 in green fluorescence and GFRA1 in red fluorescence (Figure 2A-B). CD9 was seen in red fluorescence (Figure 2E) whereas ITGA6 showed a few positive cell markers in green fluorescence (Figure 2D). DAPI staining confirms the presence of SSCs (Figure $2 \mathrm{C} \& 2 \mathrm{~F}$ ). In NOA patient sample cultured with HESC, BFGF and LIF medium showed more positive SSCs protein markers; ITGB1 in green fluorescence, GFRA1 in red fluorescence (Figure $3 \mathrm{~A}$ -B), ITGA6 in green fluorescence and CD9 in red fluorescence (Figure 3D-E). Figure $3 \mathrm{C}$ and $3 \mathrm{~F}$ showed the confirmation of SSCs in DAPI staining.

In NOA sample cultured with HESC medium supplemented with BFGF, rFSH and testosterone, there was no protein cell surface markers (SCP3 and TP1) but DAPI staining showed presence of unknown cell (Figure 4A). As for NOA sample cultured with 
HESC medium containing BFGF, LIF, rFSH and testosterone, the red fluorescent indicated the presence of SCP3 and TP1 markers (Figure 4B \&4D). DAPI staining confirmed the presence of SSCS differentiation (Figure $4 C \& 5 E$ ).
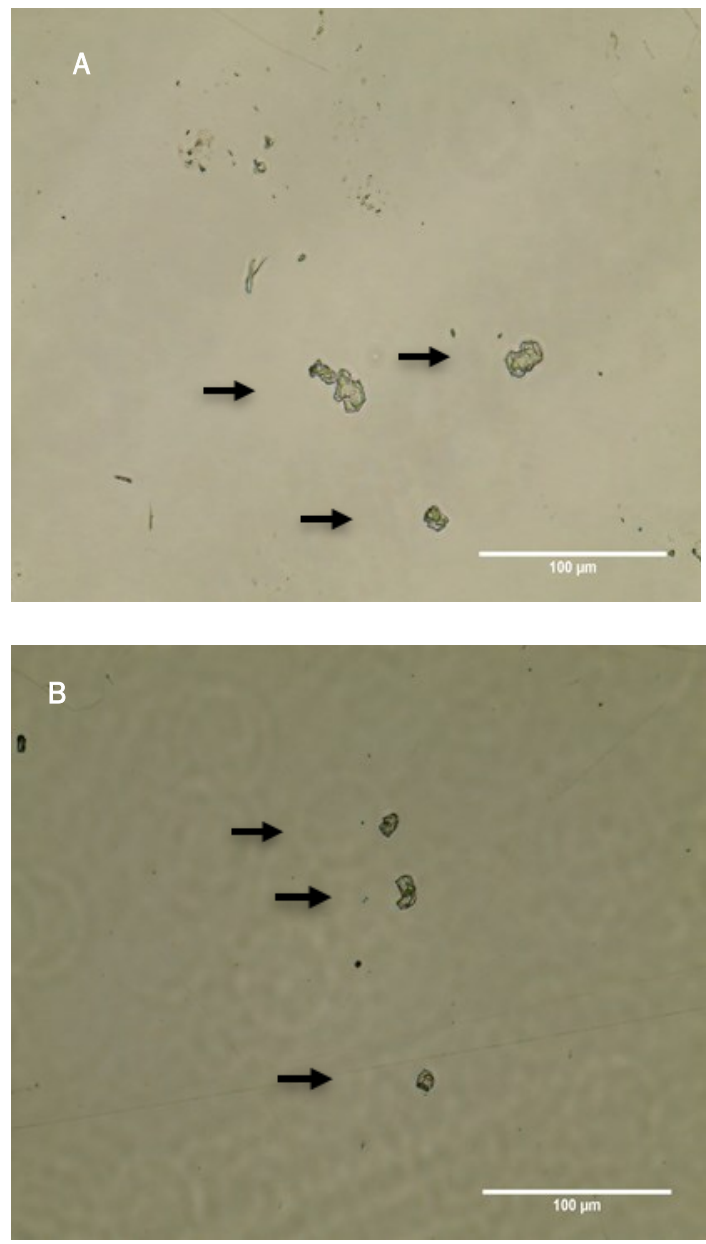
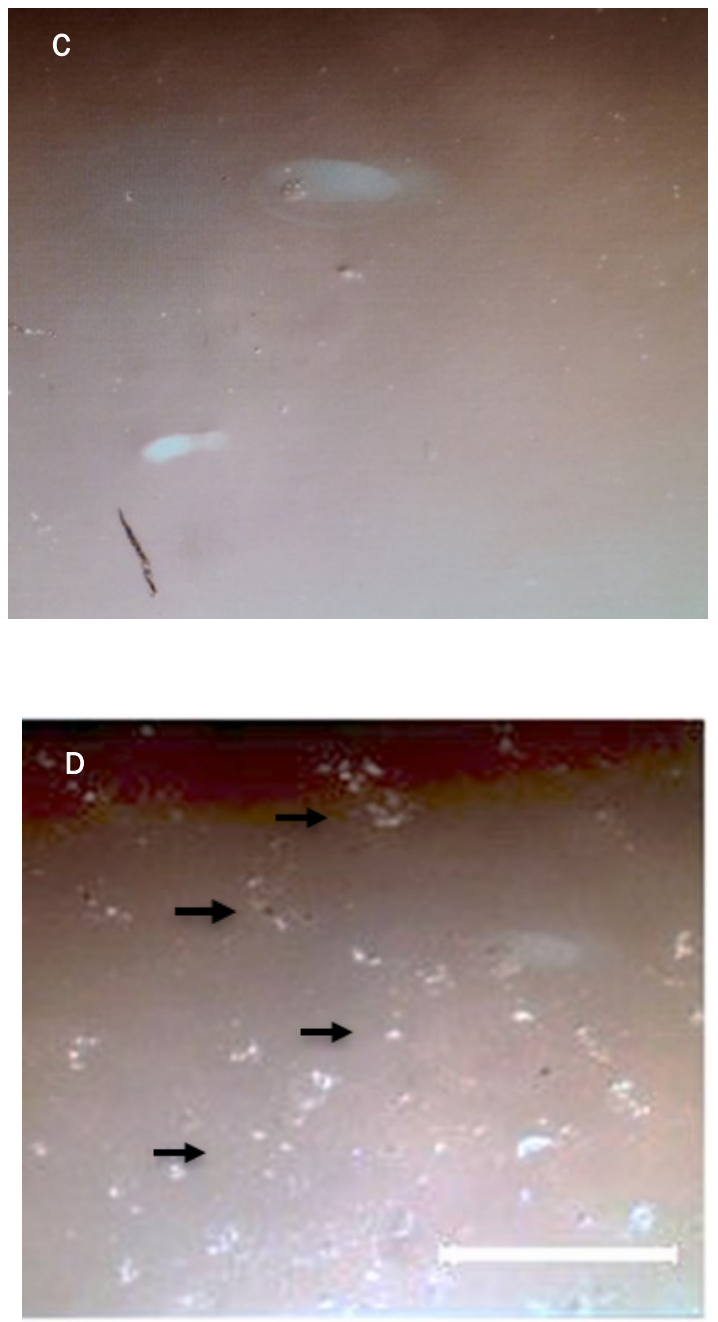

Figure 1: Propagation activity of SSCs in vitro culture condition in NOA patient sample. A: 49 days of culture with HESC and BFGF (arrows), B: 49 days of culture with HESC, BFGF and LIF (arrows). Scale bars $=100 \mu \mathrm{m}$ in A and B. The cells were observed under inverted microscope (Nikon, Germany)(200X). C: 90 days of culture with HESC and BFGF (arrows), D: 90 days of culture with HESC, BFGF and LIF (arrows). Scale bars $=25 \mu \mathrm{m}$ in A and B. The cells were observed under inverted microscope (RI Nikon, Germany) (100X).

\section{DISCUSSION}

Study on isolation, culture and identification of undifferentiated SSCs has allowed us to characterize the human testis phenotypically. SSCs are unique adult stem cells because they can undergo selfrenewal and transmit genetic information to the next generation. ${ }^{16}$ The biological study of human SSCs is a worthy research to understand the basic concept of stem cell regulation and therapy in male infertility problem such as azoospermic patient.

The establishment of specific culture system is important to maintain a specific type of self-renewal division. ${ }^{18}$ The HESC culture media was used generally for the development of undifferentiated ESCs, but it was also applicable to culture undifferentiated human SSCs. The Knockout DMEM in HESC media is a special basal medium consists of high glucose designed specifically to improve morphology and maintenance of ESCs as well as SSCs. Knockout serum replacement (KSR) contains serum-free (no serum thus identification of specific can be achieved) added as a supplement to the culture condition. The main purpose of KSR is to provide hormones and growth factors to trigger cell replication. ${ }^{11}$ Both these reagents are used together to produce less cells differentiation. The result of this study is parallel with previous study, which reported that KSR is vital for testicular organ culture, and the long-term culture of SSCs were supported by utilizing KSR. ${ }^{11,19}$ Furthermore, this study was done to determine combination of growth factor and HESC media that could support the propagation activity of SSCs population. 
Based on SSCs morphology for 49 days of culture, the propagation activity of cells formed stable colonies. It showed that the propagation of "SSCslike cells" was positively seen with presence of ITGA6, ITGB1, CD9 and GFRA1protein markers using immunofluorescent staining. These protein markers were seen more in HESC medium supplemented with BFGF and LIF medium as compared to HESC medium with only BFGF (Figure 2A, 2B, 2D, 2E, 3A, 3B, 3D and $3 E$ ). The expression of ITGA6 and ITGB1 in both of the HESC media suggested that the SSC-like cells were able to proliferate and survive in vitro. CD9 marker showed that the integrins (ITGA6 and ITGB1) might be involved in regulating and repopulating SSCs (Figure 2D and 3D).

This marker is related to C-KIT marker that is associated with differentiation of SSCs into next stage of spermatogenic cells. There is no proven study to show CD9 is the marker for B spermatogonia or primary spermatocytes cell. Positive GFRA1 marker showed intracellular SSCs signalling that controls balance between selfrenewal and differentiation of SSCs (Figure 2B and $3 B$ ). The presence of more protein markers in HESC medium containing BFGF and LIF medium suggested that one growth factor alone (BFGF) is not sufficient for SSC-like cells to propagate. Thus, more growth factors are required for proliferation of SSC-like cells as found by other researchers. ${ }^{10,12,}$ Moreover, LIF maintains the survival of SSC-like cells in longterm in vitro culture. ${ }^{15,18}$

According to previous study, combination of growth factor provides such as BFGF, LIF, EGF and GDNF were usually added into culture system for a longterm stabilization of SSCs propagation. ${ }^{16,18}$ Our study proved that combination HESC media with BFGF and LIF have a tremendous effect on long-term culture with combination of rFSH and testosterone hormones. The presence of red fluorescent in the immunofluorescent staining indicated SCP3 and TP1 protein cells were expressed (Figure $4 B$ and 4D). This suggested that SSC-like cells had undergone meiotic division; differentiate into spermatocytelike cells stage with the presence of SCP3. Moreover, positive TP1 marker showed late spermatogenesis had occurred where post-final second meiotic division differentiated into round spermatid-like cells. NOA sample cultured with HESC medium supplemented with BFGF, rFSH and testosterone revealed a different result. No protein markers were present but unknown cells occurred with DAPI staining (Figure 4A).

This would be the first successful in vitro conventional culture using human sample from NOA patient which enabled SSC-like cells to differentiate into round spermatid-like cells using HESC medium supplemented with BFGF, LIF, rFSH and testosterone. Most of the previous studies showed SSCs differentiation into post-meiotic stage in mice. ${ }^{1,14,20,22}$ There are a few in vitro studies that used NOA patient samples that achieved differentiation of spermatocytes into spermatids but using different approaches. ${ }^{14}$ So far, there is no study that shows successful development of late spermatogenesis in vitro using SSCs from human samples.

Muslims regard the Islamic faith, as a complete way of life. A multitude of nationalities practice Islam, and as a result there are various interpretations of Qur'anic guidance. Marriage is described as half the faith in Islam and having a child is great blessing. There is no religious objection for an infertile married couple pursuing any form of infertility treatment including in vitro fertilization, surgical sperm retrieval and other assisted conception methods. However, there must be strict control to ensure that the gametes belong to the husband and wife. In the Muslim world, infertile couples are usually concerned about making test-tube babies with issues of its kinship, descent and inheritance.

They seek out official Islamic opinion of IVF in the form of a fatwa. In the original Al-Azhar fatwa, reproduction outside of marriage is considered 'zina' or adultery, which is strictly forbidden or haram in Islam. Although, the third-party donation of sperm or egg does not involve the sexual "body contact", it is considered by most Islamic religious scholars to be a form of adultery. Involvement of the third-party donation or "mixture of relations" destroys a child's lineage, which is immoral and against God. Thus, many Islamic countries which practice Islam laws including Malaysia, strictly prohibit the use of sperm donation, egg donation, other forms of gamete donation including divorce or dead husband or wife and artificial insemination donor for infertility treatment. ${ }^{8,9}$

The successful outcomes from this study suggest that there is a potential to develop spermatogenesis in vitro for NOA patients to have their own heredity, as in line with Maqasid Shariah. The use of HESC medium supplemented with BFGF, LIF \& reproductive hormones (FSH and testosterone) was able to enhance the spermatogenesis process from SSC-like cells propagation until the round spermatid -like cells stage (post-meiotic II) for long-term in vitro culture until 90 days. ITGA6, ITGB1, CD9 and GFRA1 are markers for early spermatogenesis whereas SCP3 and TP1 are markers that represent the later stage of spermatogenesis (Figure 5). This study provides the possibility of a better future for Muslim NOA patients to have their own spermatozoa and biological offspring. 


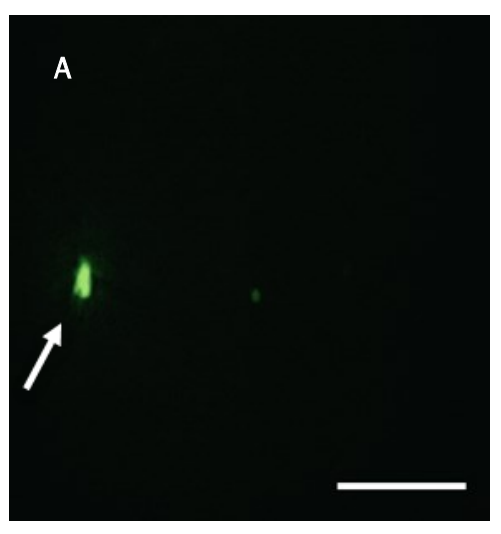

D

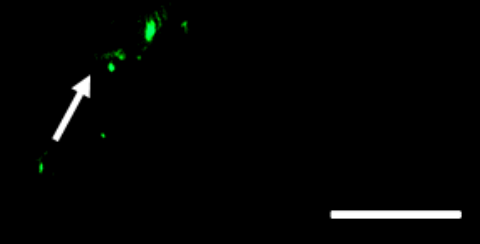

\section{B}

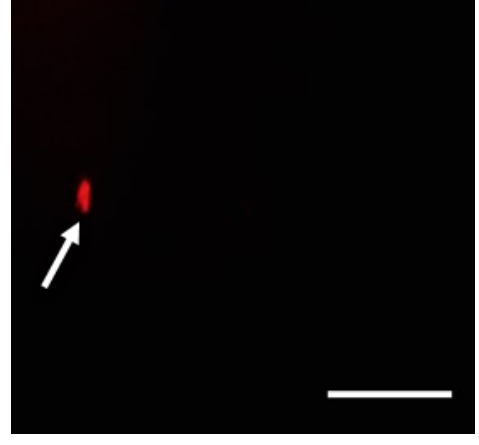

E

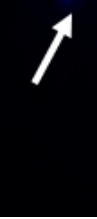

$\mathbf{F}$

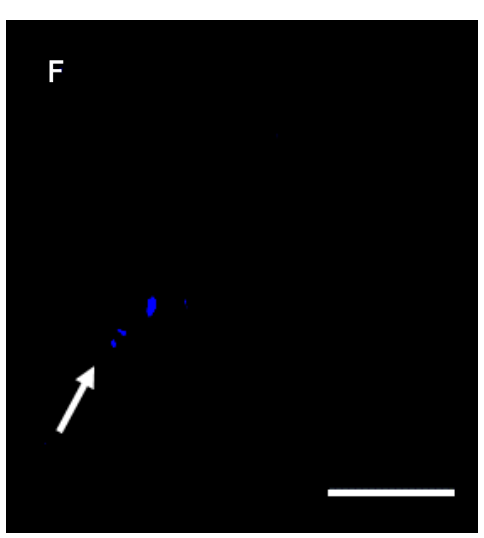

C

Figure 2: Cell surface protein markers for SSCs using IF staining from NOA sample cultured with HESC and BFGF medium. A: Green fluorescent showed positive ITGB1 protein marker (arrow); B: Red fluorescent showed positive GFRA1 protein marker (arrow); C: DAPI staining showed presence of SSCs (arrow);D: Green fluorescent showed positive ITGA6 protein marker (arrow); E: Red fluorescent showed positive CD9 protein marker (arrow); F: DAPI staining showed presence of SSCs (arrow); Scale bars $=100 \mu \mathrm{m}$ in A-F. All cells were viewed under fluorescent microscope (Nikon, Germany) (x100).
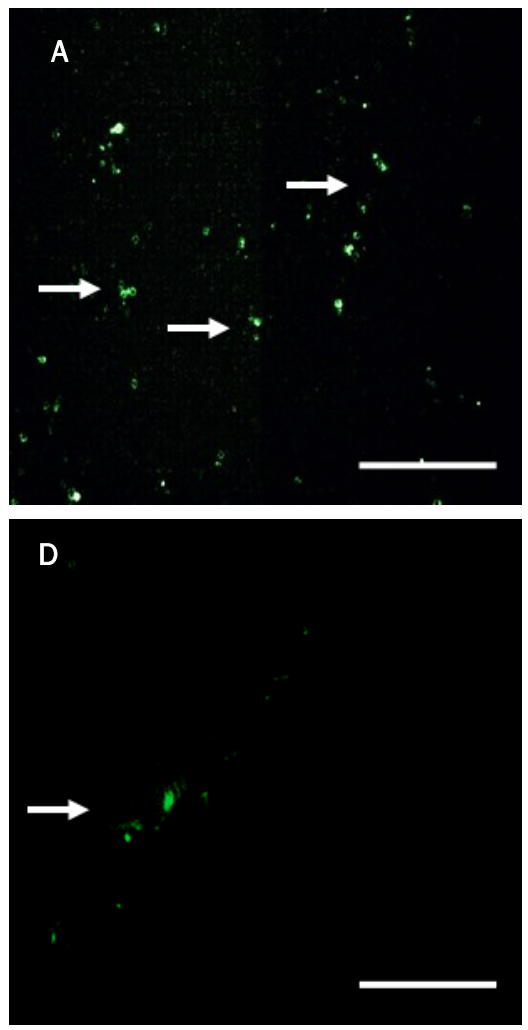

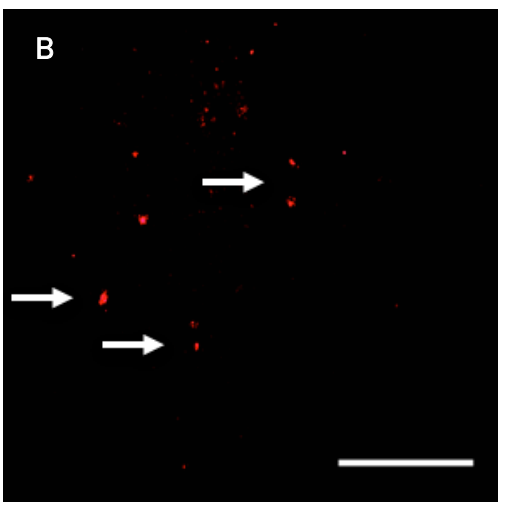

$\mathbf{E}$

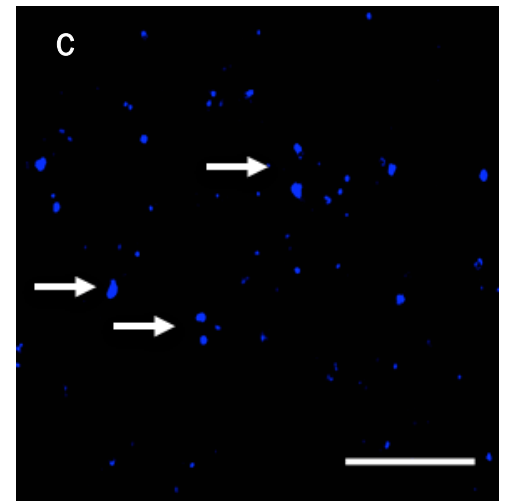

$\mathbf{F}$

Figure 3: Cell surface protein markers for SSCs using IF staining from NOA sample cultured with HESC, BFGF and LIF medium. A: Green fluorescent showed positive ITGB1 protein marker (arrows); B: Red fluorescent showed positive GFRA1 protein marker (arrows); C: DAPI staining presence of SSCs (arrows); D: Green fluorescent showed positive ITGA6 protein marker (arrow); E: Red fluorescent showed positive CD9 protein marker (arrow); F: DAPI staining showed presence of SSCs (arrow).Scale bars $=100 \mu \mathrm{m}$ in A-F. All cells were viewed under fluorescent microscope (Nikon, Germany) (x100). 

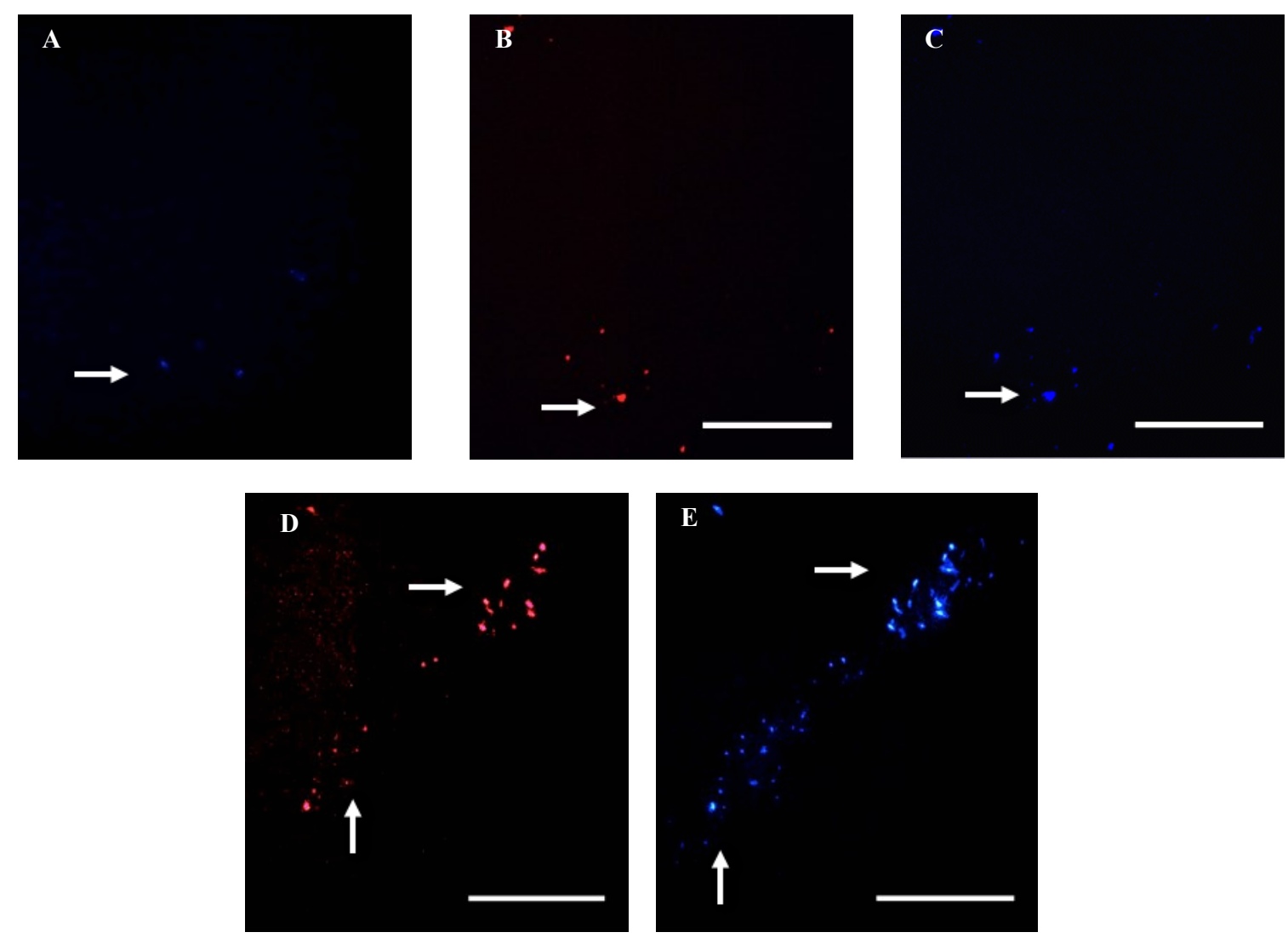

Figure 4: Cell surface protein markers for SSCs differentiation using IF staining from NOA sample cultured for 90 days. A: DAPI staining showed present of cell but not protein marker in HESC, BFGF, rFSH and testosterone hormone medium;B: Red fluorescent showed positive SCP3 protein marker in HESC, BFGF, LIF, rFSH and testosterone hormone medium(arrow);C: DAPI staining showed presence of SSCs differentiation (arrow);D: Red fluorescent showed positive TP1 protein marker in HESC, BFGF, LIF, rFSH and testosterone hormone medium (arrows); E: DAPI staining showed presence of SSCs differentiation (arrows). Scale bars $=100 \mu \mathrm{m}$ in A-C. All cells were viewed under fluorescent microscope (Nikon, Germany) (x100).

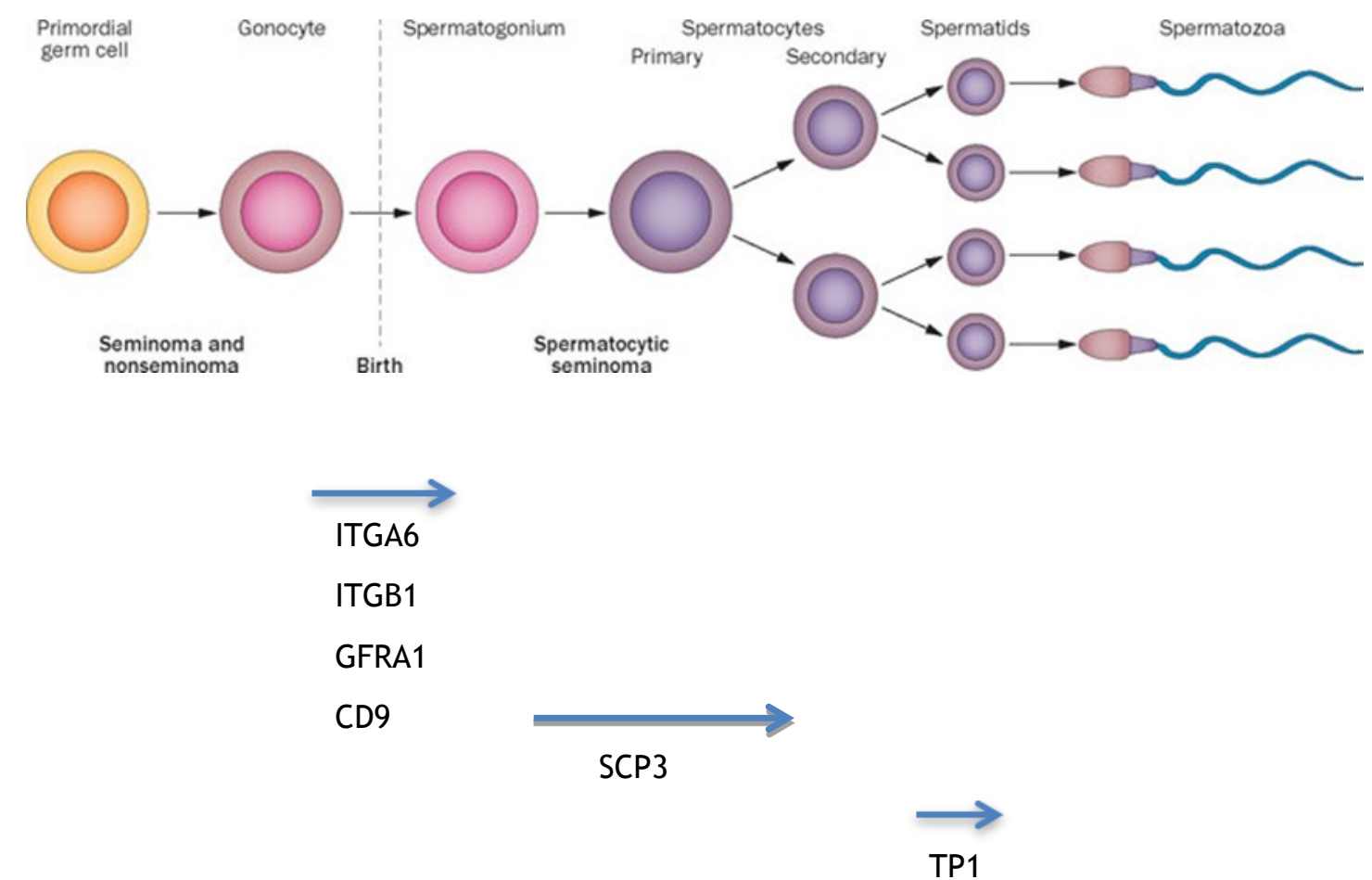

Figure 5: Protein expressions in NOA sample. 


\section{REFERENCES}

1. Abu Elhija M, Lunenfeld E, Schlatt S, Huleihel M. Differentiation of murine male germ cells to spermatozoa in a soft agar culture system. Asian J. Androl. 2011;14, 285-293.

2. Aflatoonian B, Ruban L, Jones M, Aflatoonian R, Fazeli A, Moore HD. In vitro post-meiotic germ cell development from human embryonic stem cells. Hum. Repro. 2009;24

(12): 3150-3159.

3. Cheung $\mathrm{HH}$, Rennert OM. Generation of fertile sperm in a culture dish: clinical implications.

Asian J. of Andrology. 2011;13:618-619.

4. Cocuzza M, Alvarenga C, Pagani R. The epidemiology and etiology of azoospermia. Clinics. 2013;68(S1):15-26.

5. Esteves SC, Agarwal A. Reproductive outcomes, including neonatal data, following sperm injection in men with obstructive and nonobstructive azoospermia: case series and systematic review. Clinics. 2013(a);68(S1):141 $-149$.

6. Esteves SC, Agarwal A. The azoospermic male: current knowledge and future perspectives. Clinics. 2013(b);68(S1):1-4.

7. Geijsen N, Horoschak M, Kim K, Gribnau J, Eggan K, Daley GQ. Derivation of embryonic germ cells and male gametes from embryonic stem cells. Nature. 2003;427:148-154.

8. Hussain FA. Reproductive issues from the Islamic perspective. Hum Fertil (Camb). 2000;3(2):124-128.

9. Inhorn MC. Making muslim babies: Ivf and gamete donation in sunni versus shi'a islam. Cult Med Psychiatry. 2006;30(4): 427-450.

10. Kanatsu-Shinohara, M, Miki, H, Inoue, K, Ogonuki, N, Toyokuni, S, Ogura, A, et al. Long-term culture of mouse male germline stem cells under serum-or feeder-free conditions. Biology Reproduction. 2005;72(4), 985-991.

11. Keisuke A, Ai B, Yoshinori M, Yuki O. Establishment of Alternative Culture Method for Spermatogonial Stem Cells Using Knockout Serum Replacement. PLS ONE. 2013;8(10):18.

12. Kevin TE, Jonathan RY, Xiangfan Z, Makoto $\mathrm{CN}$. The Application of Biomarkers of Spermatogonial Stem Cells for Restoring Male Fertility. IOS Press. 2008;24, 267-276.

13. Kubota H, Avarbock MR, Brinster RL. Growth factors essential for self-renewal and expansion of mouse spermatogonial stem cells. Proceeding of the National Academic Sciences(PNAS),USA. 2004;101(47), 1648916494.

14. Lee DR, Kye-Seong K, Yun HY, Hwa SO, Sook HL, Tae GC, Jung HC, Hyun JK, Tae KY, Kwang YC. Isolation of male germ stem celllike cells from testicular tissue of nonobstructive azoospermic patients and differentiation into haploid male germ cells in vitro. Human Reproduction. 2006;21(2), 471476.

15. Lim JJ, Sung SY, Kim HJ, Song SH, Hong JY, Yoon TK, et al. Long-term proliferation and characterization of human spermatogonial stem cells obtained from obstructive and non-obstructive azoospermia under exogenous feederfree culture conditions. Cell Prolif. 2010;43(4):405-17.

16. Liu S, Tang Z, Xiong T, Tang W. Isolation and Characterization of Human spermatogonial Stem Cells. Reproductive Biology and Endocrinology. 2011;9(1), 141-150.

17. Lokman $M$, Moore $H$. An artificial sperm--next year or never? Human Fertility (Cambridge).2013;13(4):272-6.

18. Piravar ZI, Jeddi TM, Sadeghi MR, Mohazzab A, Eidi A, Akhondi MM. In vitro Culture of Human Testicular Stem Cells on Feeder-Free Condition. Journal of Reproduction Infertility. 2013;14(1), 17-22.

19. Sato T, Katagiri K, Gohbara A, Inoue K, Ogonuki N. In vitro Production of Functional Sperm in Cultured Neonatal Mouse Testes. Nature. 2011;471:504-507.

20. Stukenborg JB, Schlatt S, Simoni M, Yeung $\mathrm{CH}$, Elhija MA, et al. New horizons for in vitro spermatogenesis? An update on novel threedimensional culture systems as tools for meiotic and post-meiotic differentiation of testicular germ cells. Mol. Hum. Reprod. 2009;15, 521529.

21. Toyooka Y, Tsunekawa N, Akasu R, Noce T. Embryonic stem cells form germ cells in vitro. Proceedings of the National Academy of Sciences (PNAS). 2003;100(20):11457-11462.

22. Virgier $M$, Weiss $M$, Perrard $M H$, Godet $M$, Durand $P$. The effects of FSH and of testosterone on the completion of meiosis and the very early steps of spermiogenesis of the rat: an in vitro study. J. Mol. Endocrinol. 2004;33, 729-742. 
